\title{
OPTIMIZATION PRODUCTION CONDITIONS OF ANTIBACTERIAL METABOLITE FROM STREPTOMYCES SP.
}

\author{
LINDA H AL-GHAZALI ${ }^{1}$, RABAB OMRAN ${ }^{2 *}$ \\ ${ }^{1}$ Department of Clinical Analysis, College of Applied Medical Sciences, University of Karbala, Iraq. ${ }^{2}$ Department of Biology, College of \\ Science, University of Babylon, Iraq. Email: omranaljelawi@gmail.com
}

Received: 17 April 2017, Revised and Accepted: 13 June 2017

\section{ABSTRACT}

Objectives: The paper aimed to isolate Streptomyces strain having the ability to produce antibacterial metabolites and optimize some environmental parameters for excellent antibiotic production.

Methods: Different soil samples were collected from extreme environments of desert regions at Karbala Province, Iraq. Actinomycetes were isolated using different media. The primary screening for antibacterial production was accomplished, and the antibacterial activities were tested against pathogenic bacteria, including Escherichia coli, Staphylococcus aureus, Streptococcus agalactiae, and Pseudomonas aeruginosa. The most potent strain was chosen for optimizing some of environmental parameters to increase the bioactive metabolite production. Different parameters were studied such as culture media, temperature, $\mathrm{pH}$, and agitation rate.

Results: About eight Streptomyces strains were isolated from soil samples. All isolates appeared variable levels of antibiotic productions against Grampositive and negative pathogenic bacteria, and the best one was Streptomyces sp. LHR 9. The antibacterial metabolite production from Streptomyces sp. LHR 9 was affected by various cultural parameters. Glucose soybean meal broth as a fermentation medium at pH 7 yielded the highest antibiotic production under the optimal fermentation conditions, including the temperature at $35^{\circ} \mathrm{C}$ with $200 \mathrm{rpm}$ (revolution/min) agitation rate and 7 days incubation period.

Conclusion: The Streptomyces sp. LHR 9 showed antibacterial activity against both Gram-positive and negative pathogenic bacteria. It may consider as a potential source of drug production. Further study needs to purification and characterization of antibiotic and analyzes the mechanism for the antimicrobial activity of this bioactive compound.

Keywords: Streptomyces, Antibacterial metabolite, Optimization, Environmental condition.

(c) 2017 The Authors. Published by Innovare Academic Sciences Pvt Ltd. This is an open access article under the CC BY license (http://creativecommons. org/licenses/by/4. 0/) DOI: http://dx.doi.org/10.22159/ajpcr.2017.v10i9.19243

\section{INTRODUCTION}

Actinomycetes comprise an extensive and diverse group of Grampositive aerobic mycelial bacteria. They are widely distributed group in nature, particularly the soil inhabit [1]. They have produced many important bioactive substances with high pharmaceutical values and approximately two-thirds of antibiotics [2]. Almost $80 \%$ of the world's antibiotics are known to produce from actinomycetes, mostly from the genera Streptomyces and Micromonospora [3].

According to the World Health Organization, over prescription and the continuous use of antibiotics have led to evolved the antibiotic resistance in many bacterial pathogens. Recently, the drug-resistant pathogenic bacteria have emerged more quickly than the rate of discovery of new medicines and antibiotics. Therefore, many researchers and the pharmaceutical industries have actively worked to find new sources of antibiotic production. The isolation of actinomycetes from different extreme habitats and screening for novel antibiotic productions are continually [1]. Severe infections caused by multi-resistant bacteria to commonly used antibiotics and become a major global health-care problem in the $21^{\text {st }}$ century [4]. Staphylococcus aureus and other nosocomial infection bacteria, that are responsible for different types of infections, have become resistant to most classes of antibiotics [5]. Clinicians and public health officials have faced hospital-acquired drug-resistant $S$. aureus and Pseudomonas aeruginosa which resist wide spectrum of antibiotics. Hence, there is a need to rediscover new drugs active against these drug-resistant pathogens.
The majority of the actinomycetes inhabit in soil that are essential drug sources remain uncultivable, as a result, inaccessible for novel antibiotic discovery. Goodfellow and Haynes reviewed the literature on isolation of actinomycetes and suggested that only $10 \%$ of the actinomycetes are isolated from nature [6]. Most of the antibiotics in use today are derivatives of secondary metabolites produced by actinomycetes and fungi $[7,8]$. Actinomycetes can be isolated from soil and marine sediments. Although the pharmaceutical industry has screened soils for about 50 years, only a small fraction of the surface of the globe has sampled, and only a small fraction of actinomycetes taxa has been discovered $[9,10]$. Hence, we need to screen more and more actinomycetes from different habitats for antimicrobial sources in the hope of getting some actinomycetes strains producing new antibiotics that have not been discovered yet and active against multiple drugresistant pathogens.

Filamentous soil bacteria belonging to the genus Streptomyces widely recognized as industrially relevant microorganisms because of their ability to produce many kinds of novel secondary metabolites including antibiotics and enzymes [11]. Indeed, different Streptomyces species produces about $75 \%$ of commercially and medically useful antibiotics [12].

Under different conditions, antibiotics production by Streptomyces, it is possible to improve or lose altogether, so promoting the growth and production of secondary metabolites from Streptomyces can be carried out by manipulating the nutritional, chemical, and physical parameters of the culturing conditions. The cultural factor optimization 
plays a remarkable role in the productivity and economics of the essential process [13-19]. Hence, our study was aimed to the isolation of Streptomyces sp. having the ability to produce antibacterial metabolites and optimize some environmental parameters for excellent antimicrobial metabolite production.

\section{METHODS}

\section{Actinomycetes isolation}

Soil samples (50) were collected from 10 to $15 \mathrm{~cm}$ depth of the upper surface of the ground in the desert region away from about $3 \mathrm{~km}$ from Al-Razzaza lake at Karbala Province, Iraq. The samples were placed in sterile plastic containers separately, tightly sealed and transported to the laboratory.

The collected soil samples were dried in a hot air oven at $60-65^{\circ} \mathrm{C}$ for about three hours for reducing the vegetative bacterial. Subsequently, the soil samples which containing spores of actinomycetes were transferred to sterile tubes separately and store at $4^{\circ} \mathrm{C}$ until the screening performed.

The starch-casein-nitrate-agar medium was used to isolate of actinomycetes. The medium was prepared according to the manufacturer company instructions. The $\mathrm{pH}$ value of the medium was adjusted to 7-7.2 and then sterilized in an autoclave at $121^{\circ} \mathrm{C}$ for 15 minutes. The medium was then allowed to cool to around $45-50^{\circ} \mathrm{C}$, and $1 \mathrm{ml}$ of cycloheximide $(50 \mu \mathrm{g} / \mathrm{ml})$ was added before pouring into plates. Then, the medium was poured into the plates with different thick to prevent drying during the incubation period.

One gram of dried soil sample was suspended in $9 \mathrm{ml}$ sterile normal saline to prepare the spore stock solution. Serial dilutions $\left(10^{-1}-10^{-4}\right)$ were made from the stock. Four Petri dishes containing isolation medium were cultured by transferring $0.1 \mathrm{ml}$ of the spore suspension from each dilution and spreading on the surface of agar medium using a sterile glass spreader. Then, the plates were incubated at $30^{\circ} \mathrm{C}$ for 5 days. After the incubation period, the plates were examined for typical actinomycetes colonies, which had regular round, small, opaque, compact, frequently pigmented with white, brown, gray-pink, or other colors, the colonies were examined under a light microscope to observe their colonial morphology and distinguished from fungi colonies. The isolated actinomycetes were recultured in nutrient broth and nutrient agar slants and stored at $4^{\circ} \mathrm{C}$ for further study $[20,22]$.

\section{Test organisms used in the study}

Four pathogenic bacteria, including Gram-negative (Escherichia coli and P. aeruginosa) and Gram-positive (S. aureus and Streptococcus agalactiae), were used as test microorganisms for evaluation the antibacterial activity of actinomycetes. All the tested pathogenic bacteria were obtained from Laboratory of General Health in Karbala Province.

\section{Primary screening for antibacterial activity}

Primary screening of antagonism was performed on Muller Hinton agar using the perpendicular streak plate method against four test organisms, including Gram-negative (E. coli and P. aeruginosa) and Gram-positive pathogenic bacteria ( $S$. aureus and $S$. agalactiae). The medium was prepared according to manufacturer company instructions. The actinobacterial isolate was streaked across the surface of the agar medium at the middle position of the plate and incubated at $30^{\circ} \mathrm{C}$ for 7 days, in triplicate. After that, the test organisms were streaked perpendicularly with actinobacterial growth and the space of 2-3 $\mathrm{mm}$ between two streaks. Then, the plates were incubated at $37^{\circ} \mathrm{C}$ for 2 days for the test organism growing. After that, the plates were then examined, and the presences of the clear zone between the actinobacterial growth and test microorganism indicate growth inhibition of test organisms.

\section{Secondary screening for antibacterial activity}

Actinomycetes isolates were screened for their ability to produce bioactive compounds against test microorganisms using the agar diffusion methods.
The antibacterial metabolites were produced from actinomycetes isolates using the sterile fermentation broth, which composed from (g/100 ml distilled water): $2.5 \%$ glucose, $0.5 \%$ soybean, $0.5 \% \mathrm{NaCl}, 2 \%$ $\mathrm{K}_{2} \mathrm{HPO}_{4}, 0.05 \% \mathrm{MgSO}_{4}$, and $0.01 \% \mathrm{CaCO}_{3}$ at $\mathrm{pH} 7$ [22].

The inoculum was separately prepared by cultivated the actinobacterial isolates on starch casein nitrate agar at $30^{\circ} \mathrm{C}$ for 7 days. Then, the liquid media ( $50 \mathrm{ml}$ media/250-ml Erlenmeyer flask) were incubated with two disks (6 $\mathrm{mm}$ in diameter) of actinobacterial inoculum and incubated at $30^{\circ} \mathrm{C}$ in a rotary shaker at $150 \mathrm{rpm}$ (revolution per min) for 7 days. After that, the culture broth was centrifuged at $8000 \mathrm{rpm}$ at $4^{\circ} \mathrm{C}$ for 20 minutes. The aliquot supernatant was filtered using $0.45 \mu \mathrm{m}$ membrane filter (Millipore). The filtrate of each actinobacterial isolate was tested as antibacterial metabolite [23]

For antibacterial activity determination, pathogenic bacteria were grown overnight in nutrient broth at $37^{\circ} \mathrm{C}$ for $24 \mathrm{~h}(0 . \mathrm{D}=0.5$; McFarland $1 \times 10^{8} \mathrm{CFU} / \mathrm{ml}$ ). The cultures of test organisms were streaked on Moller Hinton agar medium separately. Wells $(6 \mathrm{~mm}$ in diameter) were made in each seeded agar plate, and each well was filled with $60 \mu \mathrm{l}$ of the aliquot supernatant containing the active metabolites [24]. The plates were kept at $4^{\circ} \mathrm{C}$ for $2-4 \mathrm{~h}$ for the diffusion of the metabolites. Then, the plates were incubated at $37^{\circ} \mathrm{C}$ for $24 \mathrm{~h}$. After the incubation period, the diameter of inhibition zones was measured. Each test was in triplicate, and the activities were estimated as the mean of the diameter of the inhibition zone $[25,26]$.

The isolates which exhibited higher production of bioactive compounds were rescreened for antimicrobial activity against four pathogenic bacteria using the agar well diffusion method. The best active actinobacterial isolate was chosen for identification and antimicrobial metabolite production.

\section{Optimization of antibiotic production conditions}

The optimization of cultural conditions was determined for improving the production of antimicrobial metabolites from selected isolate. The experiments were performed as batch fermentation.

\section{Fermentation media}

The selected isolate was cultured in different types of culture media at pH 7 (50 ml media/250-ml Erlenmeyer flask), which composed of the following constituents $(\mathrm{g} / \mathrm{l})$ :

- Glucose-soybean (GS) medium: Glucose 25, soybean 5, $\mathrm{NaCl} \mathrm{5,}$ $\mathrm{K}_{2} \mathrm{HPO}_{4} 2, \mathrm{MgSO}_{4} 0.5$, and $\mathrm{CaCO}_{3} 1$ [22].

- Glucose-yeast-meat-peptone (GYMP) in medium: Glucose 10, yeast extract 1 , meat extract 4, peptone 4, and $\mathrm{NaCl} 2$ [27].

- Glucose-glycerol-soybean (GGS) medium: Glucose 15, glycerol 2.5, soybean meal 25, $\mathrm{NaCl} 2.5, \mathrm{NaNO}_{3} 4, \mathrm{~K}_{2} \mathrm{HPO}_{4} 5, \mathrm{ZnSO}_{4} 0.04$, and $\mathrm{CaCO}_{3} 0.4$ [28].

- Starch-yeast-malt-casein-peptone medium (SYMCP): Starch 10, malt extract 10, casein 3, peptone 1 , yeast extract 1 , and $\mathrm{K}_{2} \mathrm{HPO}_{4} 0.5$ [29].

- Dextrose-yeast-malt medium: Malt extract 10, dextrose 4, and yeast extract 4 [29].

All media were sterilized by autoclave at $121^{\circ} \mathrm{C}$ for 15 minutes; then, they were inoculated with the actinobacterial inoculum $(2 \mathrm{disk} / 50 \mathrm{ml}$ medium with $6 \mathrm{~mm}$ in diameter) and incubated with shaking incubator at $150 \mathrm{rpm}$ (revolutions/minute) and $30^{\circ} \mathrm{C}$ for 7 days, in triplicate for each medium.

\section{Optimization incubation temperature}

The optimum temperature for antibiotic production was determined using different incubation temperatures ranged from $15^{\circ} \mathrm{C}$ to $45^{\circ} \mathrm{C}$ with $5^{\circ} \mathrm{C}$ intervals. The optimum media at $\mathrm{pH} 7$ were inoculated with the actinobacterial isolate and incubated with shaking incubator at $150 \mathrm{rpm}$ for 7 days, in triplicate for each temperature [30].

\section{The initial $\mathrm{pH}$ value of production medium}

The effect of the initial $\mathrm{pH}$ values of production medium was studied, each $150 \mathrm{ml}$ of optimum liquid medium was adjusted to initial $\mathrm{pH}$ values ranged 
from 5 to 10 using $1 \mathrm{~N} \mathrm{HCl}$ or $\mathrm{NaOH}$, and then it distributed into three flasks (50 ml medium/250 ml flask). The media were inoculated with selected isolate and incubated at the optimum temperature with shaking incubator at $150 \mathrm{rpm}$ for 7 days, in triplicate for each $\mathrm{pH}$ value [30].

\section{Agitation rate of production medium}

The optimum medium was inoculated with the selected isolate and incubated at the optimum temperature with different agitation rates ranged from 100 to $350 \mathrm{rpm}$, in addition to the static condition (0 rpm) for 7 days, in triplicate for each agitation rate [31].

\section{Statistical analyses}

Data were analyzed using SPSS version 22 software Fisher's exact with a significant value of $<0.05$.

\section{RESULTS AND DISCUSSION}

\section{Actinomycetes isolation and antibiotic screening}

From the desert soil samples, 8 actinomycetes isolates were recovered and identified depending on microbial, cultural, biochemical, and molecular characteristics (unpublished data). These isolates were preserved in starch-casein-nitrate-agar slants at $4^{\circ} \mathrm{C}$ for further analysis.

The antibiotic screening (primary and secondary) was done against four pathogenic bacterial strains, including Gram-negative (E. coli and $P$. aeruginosa) and Gram-positive pathogenic bacteria ( $S$. aureus and $S$. agalactiae). The results revealed that all actinobacterial isolates appeared the ability to produce antibiotic substances against the test microorganisms (Table 1).

All actinobacterial isolates exhibited a broad spectrum of antibacterial activity against Gram-positive and negative bacteria. The isolate LHR 9 followed by the isolates LH 12 and LH 3 which showed the highest activity among the others. The LHR 9 isolate showed the highest antibacterial activity, according to Fisher's least significant difference (LSD) (LSD=3.565) against tested Gram-negative bacteria. It formed inhibition zones were $9.3331 .527 \mathrm{~mm}$ and $8.667 \pm 1.527 \mathrm{~mm}$ for E. coli and P. aeruginosa, respectively, whereas the isolate LH 12 gave an inhibition zone of $7.667 \pm 1.527 \mathrm{~mm}$ for E. coli and $6.000 \pm 1.000$ for P. aeruginosa. Furthermore, it had high antibacterial activity against tested Gram-positive bacteria. These results were consistent with the previous studies $[24,32,33]$ which reported the Gram-positive bacteria were more susceptible than Gram-negative bacteria to antibacterial substances that produced from actinomycetes. The moderate antibacterial activity of actinomycetes secondary metabolites against the Gram-negative bacteria could be ascribed to the presence of an outer membrane that possesses hydrophilic lipopolysaccharide chains and forms an additional barrier for the entry of antibiotic extract into the cells $[16,24,34,35]$.

Due to the highest antibacterial activity and the excellent growth properties, the isolate LHR 9 a yellowish white-colored actinomycetes was chosen for production of an antibacterial metabolite. This strain was identified according to morphological, physiological, and molecular properties and found it related to Streptomyces sp. [21] (unpublished data).

Optimization fermentation parameters of antibiotic production from Streptomyces sp.

The antimicrobial metabolite from microorganisms influences by different environmental parameters such as fermentation media composition, temperature, $\mathrm{pH}$, and agitation rate. The optimizing production conditions of any microbial product are a crucial step to stimulate overproduction from microorganisms such as actinobacterial species. Due to the most secondary metabolites such as antimicrobial substances are yielded from different pathways in microbial cells, the easiest way to improve the production is optimizing fermentation parameters. Logically, if we want to determine the effect of any parameter, must be non-changed the others, so all the experiments were designed at this trend.

\section{Fermentation media}

Preliminary, the best fermentation medium was selected depending on the results of antibiotic production from Streptomyces sp., when it was grown in five different media (Fig. 1). According to the statistical analysis $(L S D=3.751)$, the best production medium was GS medium,

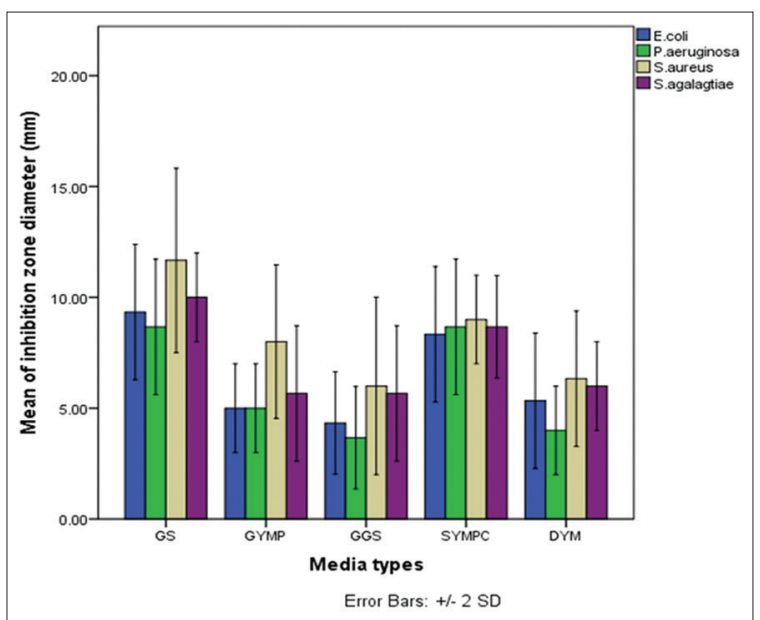

Fig. 1: Effect of different fermentation media on antimicrobial production from Streptomyces sp. LHR 9. *Least significant difference $=3.751$ at a level 0.05 ; The actinobacterial strain was grown in liquid media (pH 7) at $30^{\circ} \mathrm{C}$ and $150 \mathrm{rpm}$ for 7 days. The antibiotic activities were measured according to the agar diffusion method using Moller Hinton agar; each well ( $6 \mathrm{~mm}$ in diameter)

was filled with $60 \mu \mathrm{l}$ of the aliquot supernatant containing actinobacterial metabolites produced from Streptomyces sp. LHR 9 , and the plates were incubated at $37^{\circ} \mathrm{C}$ for $24 \mathrm{hr}$

Table 1: Secondary screening of antibiotic production from actinomycetes isolates against pathogenic bacteria

\begin{tabular}{llll}
\hline \multirow{2}{*}{ Actinomycetes } & \multicolumn{2}{l}{ Inhibition zone diameter $(\mathbf{m m}) \pm$ SD } & \multicolumn{1}{l}{ S. agalactiae } \\
\cline { 2 - 4 } & \multicolumn{1}{l}{ E. coli } & P. aeruginosa & $9.000 \pm 1.000$ \\
\hline LH 3 & $5.333 \pm 1.527$ & $5.666 \pm 1.154$ & $12.667 \pm 2.516$ \\
LH 6 & $5.667 \pm 1.154$ & $6.000 \pm 1.000$ & $10.333 \pm 1.527$ \\
LH 7 & $3.667 \pm 0.577$ & $4.333 \pm 1.527$ & $6.667 \pm 2.081$ \\
LHR 9 & $9.333 \pm 1.527$ & $8.667 \pm 1.527$ & $11.333 \pm 2.309$ \\
LH 10 & $4.000 \pm 1.732$ & $4.333 \pm 1.527$ & $6.000 \pm 1.732$ \\
LH 11 & $4.333 \pm 1.154$ & $4.000 \pm 1.000$ & $6.667 \pm 1.527$ \\
LH 12 & $7.667 \pm 1.527$ & $6.000 \pm 1.000$ & $11.000 \pm 1.000$ \\
LH 18 & $5.000 \pm 1.732$ & $4.333 \pm 2.309$ & $8.667 \pm 1.527$ \\
\hline
\end{tabular}

*Fisher's LSD (LSD=3.565) at a level 0.05. All isolates were grown in liquid media (pH 7) at $30^{\circ} \mathrm{C}$ and $150 \mathrm{rpm}$ for 7 days. The antibiotic activities were measured according to the agar diffusion method using Moller Hinton agar; each well ( $6 \mathrm{~mm}$ in diameter) was filled with $60 \mu \mathrm{l}$ of the aliquot supernatant containing actinobacterial metabolites produced from actinomycetes and the plates were incubated at $37^{\circ} \mathrm{C}$ for $24 \mathrm{hr}$. E. coli: Escherichia coli, S. aureus: Staphylococcus aureus, S. agalactiae: Streptococcus agalactiae, P. aeruginosa: Pseudomonas aeruginosa, SD: Standard deviation, LSD: Least significant difference 
which resulted highest inhibition zones of the test microorganisms, E. coli $(9.333 \pm 1.527 \mathrm{~mm}), P$ aeruginosa $(8.667 \pm 1.527 \mathrm{~mm}), S$. aureus $(11.667 \pm 2.081 \mathrm{~mm})$, and S. agalactiae $(10.000 \pm 1.000 \mathrm{~mm})$. The medium was containing the highest glucose concentration $(2.5 \%)$ and the suitable concentration of soybean meal $(0.5 \%)$, in addition to essential mineral salts. Followed by SYMCP medium which contains more complex nutrients such as carbon and nitrogen sources (starch, yeast extract, malt, casein, and peptone), but at least concentrations ranged between $1 \%$ and $0.1 \%$. While the GGS medium appeared little antibiotic production, in spite of it contains organic and inorganic carbon and nitrogen sources. It contains glucose $(1.5 \%)$, glycerol $(0.25 \%)$, soybean meal (2.5\%), and $\mathrm{NaNO}_{3}(0.4 \%)$, in addition to other essential mineral salts. These results indicate that the Streptomyces sp. LHR 9 was preferred high concentration of glucose and low concentration of nitrogen source to stimulate its growth and antimicrobial metabolites production, due to it adapted to grow in a weak nutrient environment (desert, the local of isolation). On the other hand, the composition of production medium effects on the level of antimicrobial metabolites production depending on the structural components of the antibiotics [24].

In spite of all tested media were supplemented with the necessary components such as carbon, energy sources, minerals, and growth factors for the microorganism growing. However, it appeared variable quantities of antibiotic production; this may be due to the nature of the organism and its genetic content $[21,34]$. Glucose has been found to increase the growth of Streptomyces sp. LHR 9 and antibiotic production; this result was in agreement with other investigations of the researchers who stated that glucose was the excellent carbon source for antibiotic production $[35,36]$. The presence of $\mathrm{NaCl}$ in producing medium was enhanced microbial growth because it was isolated from extreme environments. Furthermore, it induced the release of bound antibiotic from the mycelia; these results were in agreement with the result of previous studies $[24,37]$ which reported the production of the antimicrobial metabolite was increased with the presence of high concentration of glucose and sodium chloride. Soybean meal is a complex nitrogen source and contains some amino acids such as lysine, methionine, threonine, tryptophan, aspartic acid, glutamine, proline, alanine, valine, and isoleucine. The presence of tryptophan in soybean meal increases antibiotic production up to a certain level [38]. Due to the GS medium was the best fermentation medium which stimulates highest antibiotic production levels from Streptomyces sp. LHR 9, this medium was used to optimize other fermentation conditions.

These results were disagreed with studying of Mukhtar et al. [39] which concerned with the production of antitumor antibiotic from Streptomyces capoamus in batch fermentation and concluded the GYMP medium as the best medium for the production of secondary metabolites.

\section{Incubation temperature}

Any microorganism has an optimum temperature for growing but not always it is optimized for secondary metabolite production. Hence, the actinobacterial strain (Streptomyces sp. LHR 9) was grown in different incubation temperature to determine the optimum for antibiotic production using the optimum medium (GS). The preliminary experiments showed that the optimum growth temperature was $30^{\circ} \mathrm{C}$. The present results revealed that the optimum temperature for the maximum antibiotic production was $35^{\circ} \mathrm{C}$, which indicated by the increasing of inhibition zone of tested pathogenic microorganisms (LSD=5.003). The inhibition zones reached to $15.667 \pm 2.886 \mathrm{~mm}, 12.000 \pm 3.000 \mathrm{~mm}$, $19.333 \pm 2.081 \mathrm{~mm}$, and $17.000 \pm 1.000 \mathrm{~mm}$ for E. coli, P. aeruginosa, $S$. aureus, and S. agalactiae, respectively (Fig. 2). Whereas, at $30^{\circ} \mathrm{C}$, the inhibition zones were $10.000 \pm 2.000 \mathrm{~mm}, 8.000 \pm 2.000 \mathrm{~mm}, 17.333 \pm 1.527$, and $11.000 \pm 2.000 \mathrm{~mm}$ for E. coli, P. aeruginosa, S. aureus, and S. agalactiae, respectively. The isolate produced the antibiotic at a range of temperature from 20 to 45 in GS medium at pH 7, agitation 160 rpm for 7 days.

From these results, we can conclude that the optimum temperature for the antibacterial metabolite production was $35^{\circ} \mathrm{C}$ and used this

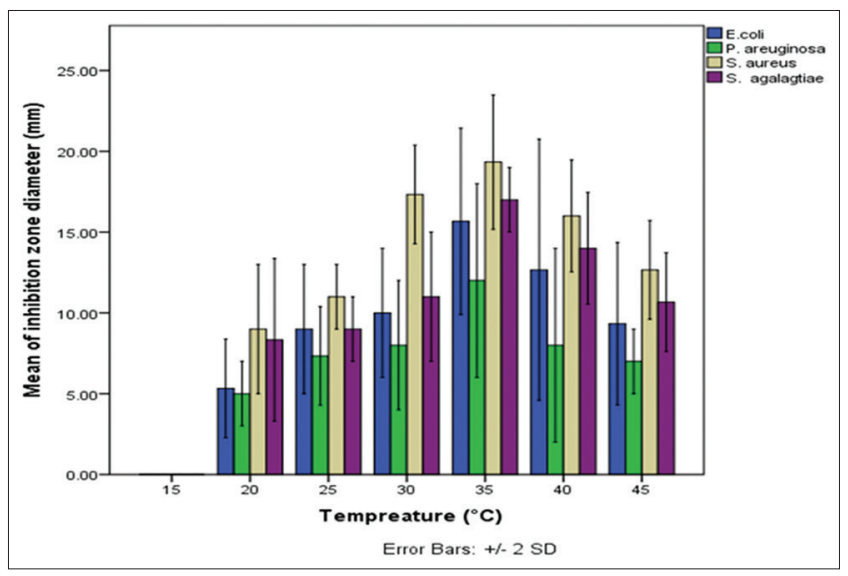

Fig. 2: Effect of incubation temperature on antimicrobial production from Streptomyces sp. LHR 9. *Least significant difference $=5.003$ at a level 0.05 ; the actinobacterial strain was grown in optimum medium GS at pH 7 and 150 rpm for 7 days and incubated at different temperatures. The antibiotic activities were measured according to the agar diffusion method using Moller Hinton agar; each well (6 $\mathrm{mm}$ in diameter) was filled with $60 \mu \mathrm{l}$ of the aliquot supernatant containing actinobacterial metabolites produced from actinobacterial strain and the plates were incubated at $37^{\circ} \mathrm{C}$ for $24 \mathrm{hr}$

degree for antibiotic production in the next experiments. Therefore, the strain was strictly mesophilic for secondary metabolite production. These results were in agreement with the results of Saha et al. [40] who studied the optimum conditions of antimicrobial metabolite production from Streptomyces sp. MNK7 and they obtained that the optimum temperature of antimicrobial fermentation was $35^{\circ} \mathrm{C}$. Furthermore, our results are consistent with previous studies of Sekhar et al. [41] and Narayana and Vijayalakshmi [42].

\section{Initial $\mathrm{pH}$ of production medium}

To determine the optimum initial $\mathrm{pH}$ value of the fermentation medium for maximum antibiotic production; the Streptomyces sp. LHR 9 was grown in GS medium at different $\mathrm{pH}$ values ranging from 5 to 10 and optimum temperature $35^{\circ} \mathrm{C}$ with agitation rate $150 \mathrm{rpm}$ for 7 days. The results revealed that the actinobacterial strain produced the antibacterial metabolite in GS medium in the different range of $\mathrm{pH}$ values (5-10). The maximum production at neutral environment pH7 (LSD=4.667); The inhibition zones were $18.333 \pm 2.516 \mathrm{~mm}$, $19.333 \pm 3.214 \mathrm{~mm}, 24.000 \pm 1.732 \mathrm{~mm}$, and $20.000 \pm 2.000$ for E. coli, P. aeruginosa, S. aureus, and S. agalactiae, respectively (Fig. 3).

The hydronium ion concentration $(\mathrm{pH})$ of the media affects the activity of cellular enzymes, nutrient ionization, and transporting through cell membranes, consequently its influence on the bacterial growth rate and secondary metabolites biosynthesis. The present results were in agreement with previous studies $[43,44]$ which reported the optimum for antibiotic production from Streptomyces species; Streptomyces hygroscopic was $\mathrm{pH} 7$ or near neutral environments. Another study said that the optimum $\mathrm{pH}$ for the fermentation of antibiotic, granaticin by Streptomyces thermoviolaceus was 6.5-7.0 and the Streptomyces isolate failed to grow at acidic $\mathrm{pH}$ but grow well at $\mathrm{pH}$ 7-8 [45].

\section{Agitation rate}

The intensity of the agitation applied during fermentation may have an impact on growth rate, antibiotic biosynthesis, metabolism through transport of nutrients and enzyme activities, cell damage, morphology, and broth viscosity in the case of non-Newtonian rheology. Hence that, the actinobacterial strain was grown in optimum GS medium at $\mathrm{pH} 7$ and different agitation speeds were applied at $35^{\circ} \mathrm{C}$ for 7 days (Fig. 4). The results appeared Streptomyces sp. LHR 9 had the ability to produce antibiotic with various agitation rates (100-350 rpm), and 
the maximum production (LSD $=4.567)$ occurred at $200 \mathrm{rpm}$ but not in static conditions $(0 \mathrm{rpm})$. That may attribute to the decrease in the agitation rate that might reduce the dissolved oxygen level in the fermentation broth that could effect on the antimicrobial metabolite production [46].

Furthermore, the agitation speed increased consequences gradually, increasing the production of antimicrobial metabolites, reaching its maximum level. The fermentation media filtrate of Streptomyces sp. LHR 9 gave inhibition zones $20.000 \pm 2.000 \mathrm{~mm}, 18.667 \pm 2.309 \mathrm{~mm}$, $26.557 \pm 1.527 \mathrm{~mm}$, and $23.333 \pm 1.527 \mathrm{~mm}$ for E. coli, P. aeruginosa, S. aureus, and S. agalactiae, respectively, at agitation speed $200 \mathrm{rpm}$. That may be a result of the aeration level in the culture medium when increased lead to sufficient supplies of dissolved oxygen in the culture media and the nutrient uptake by bacteria also will be increased. On

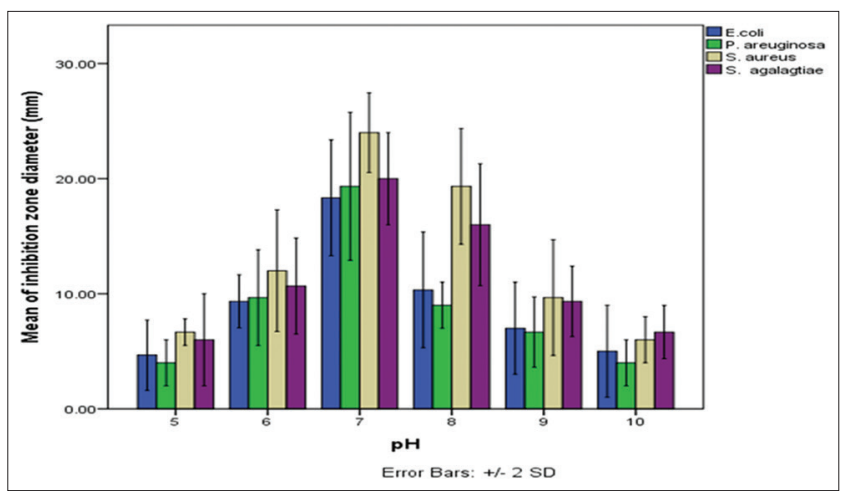

Fig. 3: Effect of different $\mathrm{pH}$ values of fermentation media on antimicrobial production from Streptomyces sp. LHR 9. *Least significant difference $=4.667$ at a level 0.05 ; The actinobacterial strain was grown in optimum medium GS in various $\mathrm{pH}$ values, at $35^{\circ} \mathrm{C}$ and $150 \mathrm{rpm}$ for 7 days. The antibiotic activities were measured according to the agar diffusion method using Moller Hinton agar; each well (6 $\mathrm{mm}$ in diameter) was filled with $60 \mu \mathrm{l}$ of the aliquot supernatant containing actinobacterial metabolites produced from actinobacterial strain, and the plates were incubated at $37^{\circ} \mathrm{C}$ for $24 \mathrm{hr}$

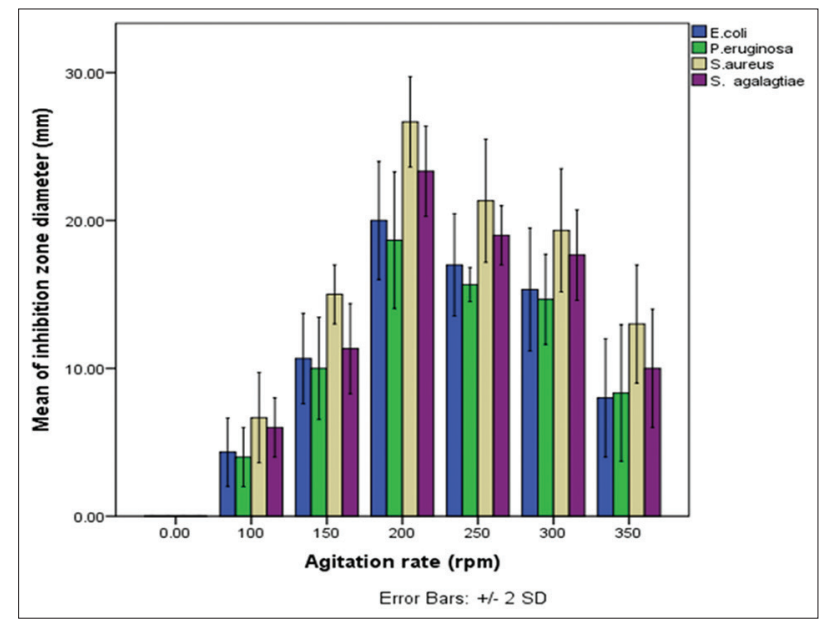

Fig. 4: Effect of agitation rates on antimicrobial production from Streptomyces sp. LHR 9. *Least significant difference $=4.567$ at a level 0.05; the actinobacterial strain was grown in optimum medium $\mathrm{GS}\left(\mathrm{pH} \mathrm{7)}\right.$ at $35^{\circ} \mathrm{C}$ for 7 days and in different agitation rates. The antibiotic activities were measured according to the agar diffusion method using Moller Hinton agar; each well ( $6 \mathrm{~mm}$ in diameter) was filled with $60 \mu \mathrm{l}$ of the aliquot supernatant containing actinobacterial metabolites produced from actinobacterial strain and the plates were incubated at $37^{\circ} \mathrm{C}$ for $24 \mathrm{hr}$ the other hand, as the agitation speed rose to $350 \mathrm{rpm}$, the activity of antimicrobial metabolites produced from Streptomyces sp. LHR 9 in fermentation media filtrate decreased gradually and reached its minimum levels as showed as inhibition zones in Fig. 4. Due to increasing the agitation speed tends to increase the amount of dissolved oxygen available to the culture that makes depletion for the cell growth and antimicrobial compound production [14].

Our results were in agreement with the findings of many researchers $[16,20,32]$ how found that the productivity increased by culture shaking in comparison with the static culture shaking in comparison with the static culture. Due to Streptomycetes are obligate aerobic organisms [21], while AL-Zahrani [34] found that the shaking culture reduced the productivity of Streptomyces J12. Whereas, other species of actinomycetes produced antibiotics under static conditions $[18,24]$.

\section{CONCLUSION}

Streptomyces sp. LHR 9 produced vital antimicrobial metabolites against Gram-positive and negative bacteria. It may act as a potential source of drug production. Further study needs to purification and characterization of antibiotic and analyze the mechanism for the antimicrobial activity of this bioactive compound.

\section{ACKNOWLEDGMENT}

The authors would like to thank the faculty of the Laboratory of Biotechnology and Genetic Engineering, Department of Biology, College of Science, University of Babylon, Iraq.

\section{REFERENCES}

1. Oskay M, Tamer AU, Azeri C. Antibacterial activity of some actinomycetes isolated from farming soils of Turkey. Afr J Biotechnol 2004;3(9):441-6.

2. Okami Y, Hotta K. Search and discovery of new antibiotics. In: Goodfellow M, Williams ST, Mordarski M, editors. Actinomycetes in Biotechnology. New York: Academic Press Inc.; 1988. p. 33-67.

3. Pandey B, Ghimire P, Agrawal VP. International Conference on the Great Himalayas: Climate, Health, Ecology, Management and Conservation, Kathmandu, Organized by Kathmandu University and the Aquatic Ecosystem Health and Management Society. Canada; 2004.

4. Alanis AJ. Resistance to antibiotics: Are we in the post-antibiotic era? Arch Med Res 2005;36(6):697-705.

5. Enright MC. The evolution of a resistant pathogen - the case of MRSA. Curr Opin Pharmacol 2003;3(5):474-9.

6. Goodfellow M, Haynes JA. Actinomycetes in marine sediments. In: Ortiz-Ortiz L, Bojalil LF, Yakoleff V, editors. Biological, Biochemical, and Biomedical Aspects of Actinomycetes. New York, USA: Academic Press; 1984. p. 453-72.

7. Butler MS, Buss AD. Natural products - The future scaffolds for novel antibiotics? Biochem Pharmacol 2006;71(7):919-29.

8. Newman DJ, Cragg GM. Natural products as sources of new drugs over the last 25 years. J Nat Prod 2007;70(3):461-77.

9. Baltz RH. Antimicrobials from actinomycetes: Back to the future. SIM News 2005;55:186-96.

10. Baltz RH. Antimicrobials from actinomycetes. Back to the future. Microbe 2007;2:125-31

11. Williams ST, Goodfellow M, Alderson G, Wellington EM, Sneath PH, Sackin MJ. Numerical classification of Streptomyces and related genera. J Gen Microbiol 1983;129(6):1743-813.

12. Miyadoh S. Research on antibiotic screening in Japan over the last decade: A producing microorganisms approach. Actinomycetologica 1993;9:100-6

13. Gopi R, Ramakrishna R, Rajagopal A. Optimization of culture conditions of Streptomyces rochei (MTCC 10109) for the production of antimicrobial metabolites. Egypt J Biol 2011;13:21-9.

14. Aman GZ. Studies on Some Actinomycete Isolate from Certain Desert Soil Samples. Ph.D. Thesis. Faculty of Science. Egypt: Al-Azhar University; 2001.

15. Jonsbu E, McIntyre M, Nielsen J. The influence of carbon sources and morphology on nystatin production by Streptomyces noursei. J Biotechnol 2002;95(2):133-44.

16. Padma PN, Rao AB, Yadav JS, Reddy G. Optimization of fermentation conditions for production of glycopeptide antibiotic vancomycin 
by Amycolatopsis orientalis. Appl Biochem Biotechnol 2002;102103(1-6):395-405.

17. El-Naggar MY, Hassan MA, Said WY, El-Aassar SA. Effect of support materials on antibiotic MSW2000 production by immobilized Streptomyces violatus. J Gen Appl Microbiol 2003;49(4):235-43.

18. Sharon SF, Daniel RR, Shenbagarathai R. Optimization of antibiotic productionby marineactinomycetes Streptomyces sp. Int J Pharm Pharm Sci 2014;6(8):506-10.

19. Kiviharju K, Leisola M, Eerikäinen T. Optimization of Streptomyces peucetius var. Caesius N47 cultivation and epsilon-rhodomycinone production using experimental designs and response surface methods. J Ind Microbiol Biotechnol 2004;31(10):475-81.

20. Venkateswarlu G, Krishna PS, Rao LV. Production of Rifamycin using Amycolatopsis mediterranei (MTCC14). Bioprocess Biosyst Eng 2004;20:27-30.

21. Kämpfer P, Order XI. Streptomycetales ord. Nov. In: Goodfellow M, Kampfer P, Busse HJ, Trujillo ME, Suzuki K, Ludwig W, editors. Bergey's Manual of Systematic Bacteriology. $2^{\text {nd }}$ ed. New York, NY: Whitman; 2012. p. 1446-806.

22. Gesheva V, Ivanova V, Gesheva R. Effects of nutrients on the production of AK-111-81 macrolide antibiotic by Streptomyces hygroscopicus. Microbiol Res 2005;160(3):243-8.

23. Karthick L, Kumar KV, Bhaskara RA. Diversity of marine actinomycetes from Nicobar marine sediments and its antifungal activity. Int J Pharm Pharm Sci 2010;2(1):199-203.

24. Omran R, Kadhem MF. Production, purification, and characterization of bioactive metabolites produced from rare actinobacteria Pseudonocardia alni. Asian J Pharm Clin Res 2016;9:264-72.

25. Shahrokhi S, Bonjar GH, Saadoun I. Biological control of potato isolate of Rhizoctoniasolani by Streptomyces olivaceus strain 115 . Biotechnology 2005;4(2):132-8.

26. Kavanagh F. Analytical Microbiology. Vol. 2. New York: Aead Press; 1972.

27. Emerson RL, Whiffen AJ, Bohonos N, Deboer C. Studies on the production of antibiotics by actinomycetes and molds. J Bacteriol 1946;52(3):357-66.

28. Pavani M, Girija SG, Prabhakar T, Bhavani A, Sravani P. Optimization and production of bioactive metabolite from Streptomyces malaysiesis TMS1a. Int J Pharm Sci Rev Res 2014;25:192-6.

29. Maataoui H, Iraqui M, Jihani S, Ibnsouda S, Haggoud A. Isolation, characterization and antimicrobial activity of a Streptomyces strain isolated from deteriorated wood. Afr J Microbiol Res 2014;8:1178-86.

30. Paul AK, Banerjee AK. Determination of optimum conditions for antibiotic production by Streptomyces galbus. Folia Microbiol (Praha) 1983;28(5):397-405

31. Singh LS, Mazumder S, Bora TC. Optimization of process parameters for growth and bioactive metabolite produced by a salt-tolerant and alkaliphilic actinomycete, Streptomyces tanashiensis strain A2D. J Mycol Méd 2009;19(4):225-33.

32. Hassan M, El-Naggar M, Said W. Physiological factors affecting the production of an antimicrobial substance by Streptomyces violatus in batch culture. Egypt J Biol 2001;3:1-10.

33. Anansiriwattana W, Tanasupawat S, Amnuoypol S, Suwanborirux K. Identification and antimicrobial activities of actinomycetes from soils in Samed Island, and geldamycin from strain PC4-3. Thai J Pharm Sci 2006;30:49-56.

34. Al-Zahrani S. Studies on the antimicrobial activity of Streptomyces sp. Isolated from Jazan. J Kau Sci 2007;19:127-38.

35. Ripa FA, Nikkon F, Zaman S, Khondkar P. Optimal conditions for antimicrobial metabolites production from a new Streptomyces sp. RUPA08PR isolated from Bangladeshi soil. Mycobiology 2009;37(3):211-4.

36. Raytapadar S, Paul AK. Production of an antifungal antibiotic by Streptomyces aburaviensis 1DA-28. Microbiol Res 2001;155(4):315-23.

37. Ramesh S, Mathivanan N. Screening of marine actinomycetes isolated from the Bay of Bengal, India for antimicrobial activity and industrial enzymes. World J Microbiol Biotechnol 2009;25:2103-11.

38. Basilio A, González I, Vicente MF, Gorrochategui J, Cabello A, González A, et al. Patterns of antimicrobial activities from soil actinomycetes isolated under different conditions of $\mathrm{pH}$ and salinity. J Appl Microbiol 2003;95(4):814-23.

39. Mukhtar H, Ijaz S, Ikram-Ul-Haq IS. Production of antitumor antibiotic by Streptomyces capoamus. Pak J Bot 2012;44(1):445-52.

40. Saha MR, Ripa FA, Islam MZ, Khondkar P. Optimization of conditions and in vitro antibacterial activity of secondary metabolite isolated from Streptomyces sp. MNK7. J Appl Sci Res 2010;6(5):453-9.

41. Sekhar MC, Krishna ER, Talluri VP, Mohan CH. Optimization of media formulation for bacterial isolate Msb-6. Int J Pharm Chem Biol Sci 2013;3:1066-9.

42. Narayana KJ, Vijayalakshmi M. Optimization of antimicrobal metabolites production by Streptomyces albidoflavus. Res J Pharm 2008;2:4-7.

43. Thakur D, BoraTC, Bordoloi GN, Mazumdar S. Influence of nutrition and culturing conditions for optimum growth and antimicrobial metabolite production by Streptomyces sp. 201. J Med Mycol 2009;19:161-7.

44. Yu J, Liu Q, Liu Q, Liu X, Sun Q, Yan J, et al. Effect of liquid culture requirements on antifungal antibiotic production by Streptomyces rimosus MY02. Bioresour Technol 2008;99(6):2087-91.

45. Manjula C, Rajaguru P, Muthuselvam M. Screening for antibioticsensitivity of free and immobolized actinomycetes isolated from India. Adv Biol Res 2009;3(3-4):84-8.

46. Elattal NA, Hamdy AA, Ali AE, Amin MA. Nystatin production by a local Streptmyces sp. Isolated from Egyptian soil. J Pharm Biomed Sci 2011;1(6):128-36 